\title{
The Effects Of Myofascial Release Technique Combined With Core Stabilization Exercise In Elderly With Non-Specific Low Back Pain: A Randomized Controlled, Single-Blind Study
}

This article was published in the following Dove Press journal:

Clinical Interventions in Aging

\author{
Gulsah Ozsoy (D) \\ Nursen Ilcin (D) ${ }^{2}$ \\ Ismail Ozsoy (D) \\ Barıș Gurpinar (D) ${ }^{2}$ \\ Oznur Buyukturan (1D' \\ Buket Buyukturan (ID) \\ Caner Kararti (iD)' \\ Senem Sas $(\mathbb{D})^{3}$ \\ 'School of Physical Therapy and \\ Rehabilitation, Kırsehir Ahi Evran \\ University, Kırsehir, Turkey; ${ }^{2}$ School of \\ Physical Therapy and Rehabilitation, \\ Dokuz Eylül University, Izmir, Turkey; \\ ${ }^{3}$ Department of Physical Medicine and \\ Rehabilitation, Kırsehir Ahi Evran \\ University Training and Research \\ Hospital, Kırșehir, Turkey
}

Purpose: To evaluate the effects of Myofascial Release Technique (MRT) with a roller massager combined with core stabilization exercises (CSE) in elderly with non-specific low back pain (NSLBP).

Patients and methods: A total of forty-five participants were randomly divided into two groups (CSE and CSE+MRT). A core stabilization exercise program was applied for the participants in the CSE group for 3 days per week for a total of 6 weeks. In addition to the core stabilization exercises, myofascial relaxation technique with a roller massager was performed for 3 days per week for 6 weeks for the participants in the CSE+MRT group. Participants were assessed in terms of pain, low back disability, lower body flexibility, kinesiophobia, core stability endurance, spinal mobility, gait characteristics and quality of life both pre- and post-treatment.

Results: It was found that the improvement in core stability endurance $(\mathrm{p}=0.031)$ and spinal mobility (in the sagittal plane) $(\mathrm{p}=0.022)$ was greater in the CSE+MRT group compared to the CSE group. There was no significant difference between the two groups in terms of pain, low back disability, lower body flexibility, kinesiophobia, gait characteristics and quality of life $(\mathrm{p}>0.05)$.

Conclusion: The current study suggests that myofascial release technique with a roller massager combined with core stabilization exercises can be a better choice in the treatment of NSLBP in elderly.

ClinicalTrials.gov Identifier: NCT03898089.

Keywords: myofascial release technique, core stabilization exercises, non-specific low back pain

\section{Introduction}

Low back pain (LBP) is a symptom that is an important health problem throughout the world. ${ }^{1,2}$ Non-specific low back pain (NSLBP) is the most widespread form of LBP. $^{3}$ NSLBP is called LBP without recognizable specific underlying pathology. ${ }^{4}$ The prevalence and burden of LBP increases with aging. ${ }^{5}$ This situation is more common and complex in elderly people. ${ }^{6,7}$

Because of the changes in fascia structures, dysfunction of deep muscles of back and trunk is common in chronic LBP. ${ }^{8,9}$ Injuries of low back are mostly caused from the superficial back line (SBL). ${ }^{10}$ The SBL contains the plantar fascia, gastrocnemius muscles, hamstring muscles, sacrolumbar fascia, erector spinae muscles and
Correspondence: Gulsah Ozsoy

Rehabilitation, Kırsehir Ahi Evran

University, Kırsehir, Turkey

Tel +905534802563

Fax +90386280537

Email fzt.gulsah@hotmail.com 
epicranial fascia. ${ }^{10}$ The deep muscles of back and trunk are attached to the superficial back line via thoracolumbar fascia. ${ }^{11}$ These deep muscles and fascia of the trunk form a continuous musculofascial corset-like system. ${ }^{8,12}$ Chronic LBP is caused by deep muscle dysfunctions and altered fascia structures. In this case, it can cause the continuous musculofascial corset-like system to fail. ${ }^{8}$ In addition, changes in fascia due to aging (increased fascial thickness and disruption of the fascial alignment) may further affect this system. ${ }^{13}$ Several studies have shown that decreased strength in the deep muscles (the transverse abdominis and multifidus) is accompanied by increased activation in the superficial muscles (such as the erector spinae) in patients with LBP. ${ }^{14-16}$ Consequently, increased activation of erector spinae can affect the tensegrity of the fascia along SBL in individuals with LBP. ${ }^{10}$

The use of various non-pharmacological and non-invasive methods such as exercise, mobilization, and manipulation is well known in LBP treatment. ${ }^{3,17,18}$ Core stability exercise is a common exercise modality in the treatment of LBP. ${ }^{19}$ To decrease pain and increase backspecific functional status in patients with LBP, core stability exercise is more effective than general exercise. ${ }^{20}$ Core stability exercises improve the strength of deep muscles of trunk and low back disability in older adult women with NSLBP. ${ }^{21}$ Myofascial release technique is another method among the possible management options in the treatment of chronic musculoskeletal pain. ${ }^{22}$ It has been demonstrated that myofascial release technique produces a significant improvement in both pain and disability. ${ }^{23}$ However, there is no study in which myofascial release technique is performed along SBL in patients with LBP.

Although the effects of core stability exercise and myofascial release technique on LBP are known separately, their effects are not yet known when applied together. To the best of our knowledge, there is no randomized controlled study investigating the effects of the myofascial release technique with a roller massager combined with core stabilization in elderly with NSLBP. Therefore, the aim of the current study was to strengthen deep muscles through core stability exercises and decrease SBL activation with myofascial release technique and investigate all the possible effects.

\section{Materials And Methods}

\section{Study Design}

This study was designed as a single blind randomized controlled study. The patients were randomly (a matched randomization method based on gender and age) divided into two groups as the core stability exercise (CSE) group and core stability exercise and myofascial release technique (CSE+MRT) group. Before and after the treatment, all assessments were evaluated by a researcher who was blind to the groups.

\section{Participants}

Patients older than 65 years with NSLBP were included in this study. The inclusion criteria of the study were ongoing LBP for at least 3 months, having no neurological or orthopedic problems, and Standardized Mini-Mental State score equal to or greater than 24 points. Patients who had LBP originating from various pathologies, such as presence of cord compression, radiculopathy, osteoporosis or osteopenia ( $t$ score $>-1$ ), as well as those who received any treatment for their LBP using long-term anticoagulant or corticosteroid drugs were excluded from the study. All the participants provided written informed consent to participate in the study. The study was conducted in accordance with the Declaration of Helsinki standards. This study was approved by the ethics committee of Dokuz Eylül University (2019/03-32).

\section{Outcome Measures}

\section{Primary Outcome Measures}

\section{Pain Severity}

The visual analog scale (VAS) was used to assess the severity of pain at rest and during activity. VAS provides a rapid (statistically measurable and reproducible) classification of pain severity. Patients marked the severity of their pain on a 10 -cm-long line $(0=$ no pain, $10=$ the worst pain possible $){ }^{24}$

\section{Pain Pressure Threshold}

It is defined as the minimum force applied that induces pain. An electronic pressure algometer (Algometer commander, JTech Medical, Line; Salt Lake City) was used to measure pressure pain thresholds (PPTs) with a stimulation surface area of $1 \mathrm{~cm}^{2}$. Three consecutive measurements were performed at each site, with $10 \mathrm{~s}$ of recovery time allowed between repeated applications. During the algometric measurements, the subjects were asked to say "yes" when they felt pain. The amount of pressure-causing pain was recorded as PPT in $\mathrm{kg} / \mathrm{cm}^{2}$. The patients were in a prone lying position for the measurements. Two lumbar paravertebral points (bilaterally $5 \mathrm{~cm}$ lateral to the $\mathrm{L} 3$ spinous processes) were evaluated. The average of the scores of the two sides was recorded as the total score. ${ }^{25}$ 


\section{Low Back Disability}

Physical disability due to NSLBP was assessed using the Oswestry Disability Index (ODI), which is a self-administered questionnaire to evaluate the limitations of various daily living activities. The ODI is one of the most common scoring systems used for patients with LBP. The total score ranges from 0 to 100 , where a higher score indicates a higher level of disability. ${ }^{26}$

\section{Secondary Outcome Measures Lower Body Flexibility}

Chair Sit and Reach Test (CSRT) was used to assess lower body flexibility. Patients were asked to sit on the edge of a chair with one leg extended and the other leg flexed. Then, they placed one hand over the other and reached forward to the toe of the extended leg. The distance between the middle finger and the toe was measured. The score was recorded as the distance reached, either a negative score or a positive score. $^{27}$

\section{Kinesiophobia}

Tampa Scale of Kinesiophobia (TSK) was used to assess the kinesiophobia, ie, the patient's fear of pain or re-injury due to movement. The TSK consists of 17 items that are scored on a 4-point Likert scale (total score ranges from 17 to 68). Higher score indicates higher levels of kinesiophobia. ${ }^{28}$

\section{Core Stability Endurance}

Supine Bridge Test was used to assess the core stability endurance. Subjects were asked to lie down in hooked position. They were asked to lift their hips from the bed. The time for the patient to hold his bridge position was measured and recorded in seconds. ${ }^{29}$

\section{Spinal Mobility Assessment}

A hand-held, computer-assisted electromechanical device (the Spinal Mouse System, Idiag, Fehraltorf, Switzerland) was used to assess spinal mobility. Measurements were performed between spinous process of $\mathrm{C} 7$ and the top of the anal crease (approximately S3). Maximal extension, maximal flexion and maximal left and right lateral flexion positions were performed. The analysis of spinal mobility in the sagittal (SAP - maximal extension to flexion) and the coronal (CRP - maximal left to right flexion) plane was evaluated. ${ }^{30}$

\section{Gait Characteristics}

The gait characteristics of patients were assessed using Biodex Gait Trainer 2 (Biodex Medical Systems Inc.), which consisted of a motorized treadmill system. The test was performed in accordance with the method described by Newell et al. ${ }^{31}$ Participants walked on the treadmill at their preferred walking speed for a period of 6 mins. The gait characteristics (walking speed, step cycle, step length, coefficient of variation, time on each foot, ambulation index result, and total distance) were recorded.

\section{Quality Of Life}

The quality of life was assessed using The World Health Organization Quality of Life Instrument-Older Adults Module (WHOQOL-OLD). This questionnaire consists of a total of 24 items listed in six different domains (sensory abilities, autonomy, past, present, and future activities, social participation, death and dying, and intimacy). Higher scores indicate better quality of life. ${ }^{32}$

\section{Treatment Programs}

A total of forty-five participants who met the inclusion criteria and volunteered to participate were randomly divided into two groups (CSE and CSE+MRT). Heat modality (a hot pack for 15 mins) and electrotherapy (transcutaneous electrical nerve stimulation (TENS), a $50-\mathrm{Hz}$ conventional TENS with a pulse duration $<150 \mu \mathrm{s})$, were applied to all participants.

\section{Core Stability Exercise Group}

A core stabilization exercise program was applied to the participants of the CSE group for 3 days per week for 6 weeks with a total of 18 sessions. Each training session lasted for 60 mins, starting with a 10-min warm-up program and ending with a 5-min cool-down program. All patients began with learning to activate the abdominal wall musculature as the first stage of core stability training. Progression of exercises was tailored according to each patient's ability, fatigue and pain. Exercises were designed from 1 set to 3 sets, from 8 to 15 repetitions and contractions from $5 \mathrm{~s}$ to $10 \mathrm{~s}$. Rest intervals were set as $30 \mathrm{~s}$ between the sets and 2-3 mins between the exercises.

All patients performed abdominal hollowing and bracing to facilitate activation of the transversus abdominis and internal oblique muscles. Once these activation techniques were learned and the transversus abdominis was "“activated", upper extremity exercises were added. Initial exercises were done in supine, hook-lying, or quadruped positions. Once a patient demonstrated good control (ie was able to complete 3 sets of each exercise, with 15 repetitions or 10-s-long contraction), he would gradually pass on into intermediate level exercises. Plank exercises were added in this level. At the 
advanced exercise level, unstable surfaces were used during the exercises. For an example, see Figure 1A-I. The contents of the exercises are specified in Table $1 .^{33,34}$

\section{Core Stability Exercise And Myofascial Release Technique Group}

In addition to the core stabilization exercises, myofascial relaxation technique was performed with a roller massager (Theraband $^{\circledR}$, The Hygenic Corporation, Akron, OH) for 3 days per week for a total of 6 weeks. The roller massage is a type of self or assisted massage that uses a device to manipulate the skin, myofascia, muscles and tendons with direct compression. ${ }^{35}$ Myofascial relaxation was done to the anatomical structures indicated by the roller massage technique. The myofascial relaxation technique with roller massager was performed along the superficial back line (from plantar surface of toe phalanges to occiput) bilaterally. ${ }^{10}$ The roller massage application was carried out along four separate myofascial tracks (plantar fascia and short toe flexors, gastrocnemius/Achilles tendon,

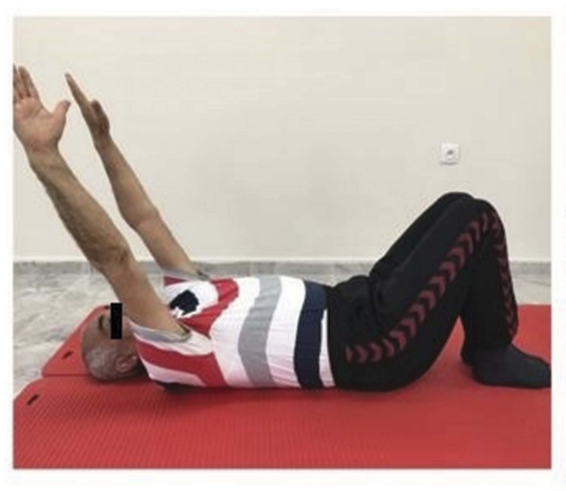

a

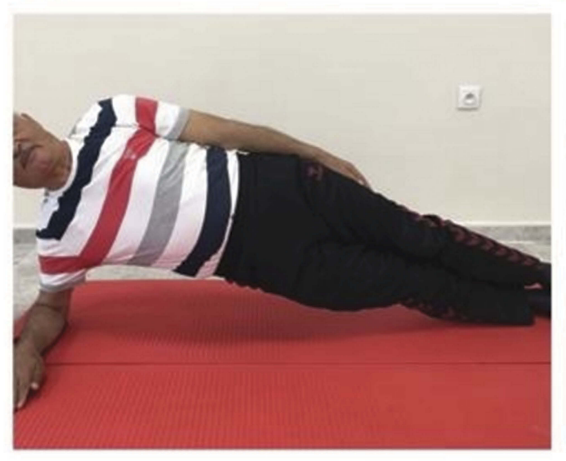

d

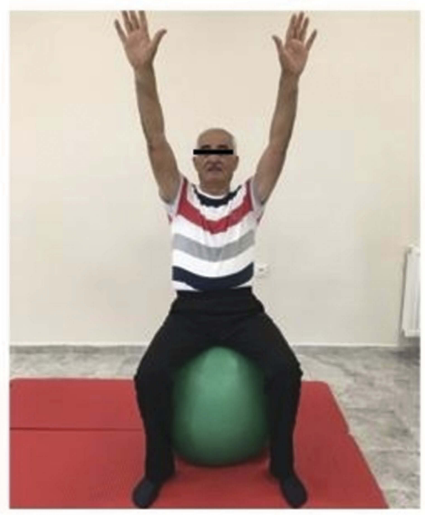

g

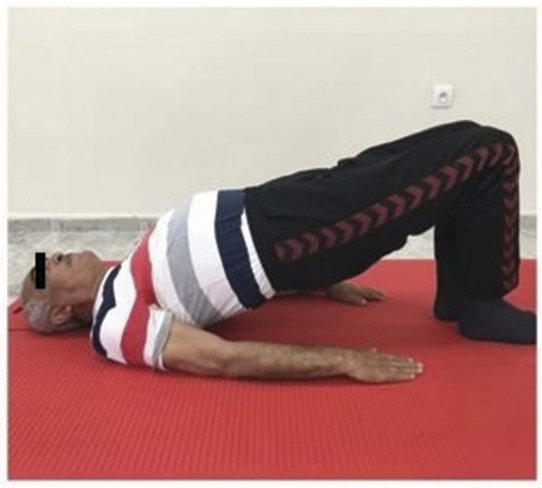

b

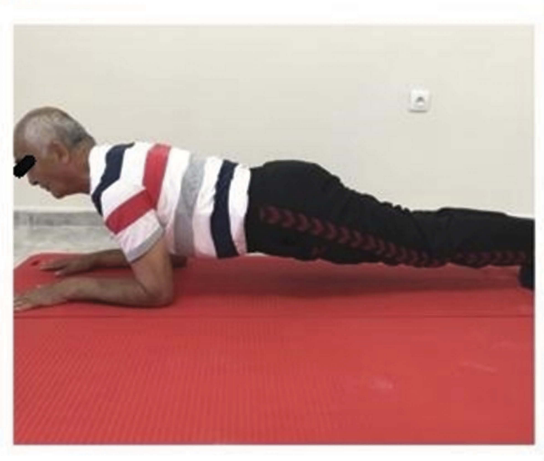

e

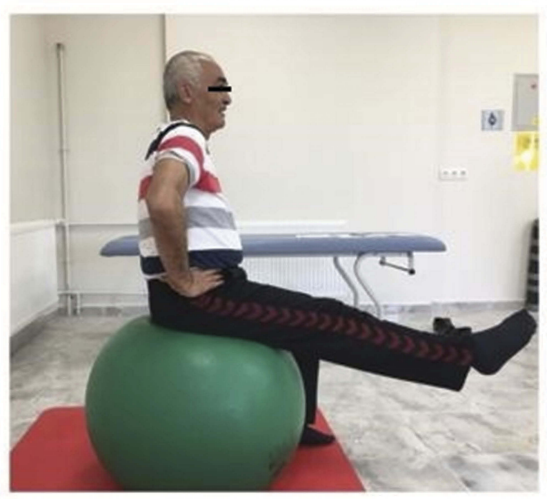

h

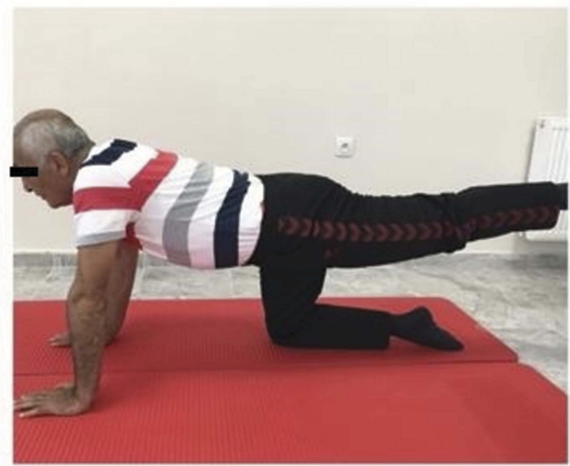

C

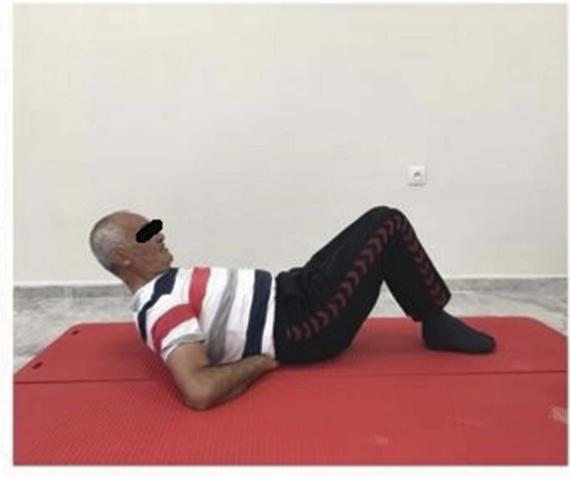

f

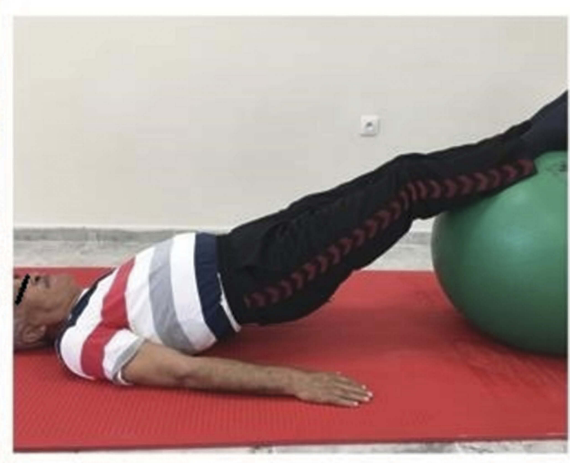

i

Figure I Examples of core stabilization exercises: beginner (A-C), intermediate (D-F), advanced (G-I). 
Table I Core Stability Exercise Program

\begin{tabular}{|c|c|c|}
\hline Beginner & Intermediate & Advanced \\
\hline $\begin{array}{l}\text { Activation of } \operatorname{TrA} \text { and } M L \text { muscles in supine hook } \\
\text { position }\end{array}$ & $\begin{array}{l}\text { Modified plank exercise on side lying } \\
\text { (knees flexed) }\end{array}$ & Supine bridge on swiss ball \\
\hline $\begin{array}{l}\text { Training of the continuation of the neutral } \\
\text { lumbopelvic control during exercises }\end{array}$ & $\begin{array}{l}\text { Plank exercise on the side lying (knees } \\
\text { extended) }\end{array}$ & $\begin{array}{l}\text { Pelvic tilt with core stabilization while sitting on } \\
\text { swiss ball }\end{array}$ \\
\hline $\begin{array}{l}\text { Upper and lower extremity exercises with core } \\
\text { stabilization }\end{array}$ & $\begin{array}{l}\text { Modified plank exercise (in knees flexed, } \\
\text { modified push up position) }\end{array}$ & $\begin{array}{l}\text { Upper extremity elevation with core } \\
\text { stabilization while sitting on swiss ball }\end{array}$ \\
\hline Supine bridge with core stabilization & Plank exercise (knees extended) & $\begin{array}{l}\text { Knee extension with core stabilization while } \\
\text { sitting on swiss ball }\end{array}$ \\
\hline $\begin{array}{l}\text { Upper and lower extremity exercises in crawling } \\
\text { position with core stabilization }\end{array}$ & Curl up exercise & Sit and stand exercise with core stabilization \\
\hline
\end{tabular}

hamstrings and sacrolumbar fascia/erector spinae) of the superficial back line. The applications were done in prone and standing positions (Table 2). The technique was repeated in 3 sets ( $1 \mathrm{~min}$ rest between sets) lasting for $30 \mathrm{~s}$ for each myofascial track. ${ }^{35}$ In accordance with the literature, the intensity of rolling massage was adjusted to ensure that $7 / 10$ on the VAS was maintained. ${ }^{36-38}$ For an example, see Figure 2A,B.

\section{Sample Size}

There is no study in the literature investigating the effects of myofascial release technique combined with core stabilization exercises in elderly with NSLBP. However, a previous study demonstrated that core stability exercises had a significant impact on pain in patients with chronic NSLBP $(p<0.05) .{ }^{39}$ Based on the results of that study, the minimum required sample size for analysis was calculated as 19 participants per group for the probability level as 0.05 , the anticipated effect size as 0.69 , and the statistical power level as $80 \%$ using G*Power Software (Version 3.1.9.2, Düsseldorf University, Düsseldorf, Germany). Allowing for a 15\% dropout rate, 45 subjects were recruited into the study.

\section{Data Analysis}

The data were analyzed using the IBM $^{\circledR}$ SPSS $^{\circledR}$ Statistics for Windows software (Version 20.0. Armonk, NY: IBM Corp.). Kolmogorov-Smirnov test was used to check normality. Values were expressed as mean \pm standard deviation and median (25-75 quartiles) for continuous variables, and frequencies were reported for categorical variables. Independent samples $t$-test (when samples met parametric conditions) and Mann-Whitney $U$-test (when samples did not meet parametric conditions) were used to compare the continuous variables between the two groups. Chi-square test was used to compare the categorical variables between the two groups. The paired sample $t$-test

Table 2 Details Of The Superficial Back Line And Patients' Positions

\begin{tabular}{|l|l|l|}
\hline Myofascial Tracks & Bony Landmarks & Patients' Position \\
\hline $\begin{array}{l}\text { Plantar fascia and short toe } \\
\text { flexors }\end{array}$ & $\begin{array}{l}\text { Plantar surface of toe phalanges- } \\
\text { calcaneus }\end{array}$ & Standing position supported with one hand from the wall \\
\hline Gastrocnemius/Achilles tendon & Calcaneus-condyles of femur & $\begin{array}{l}\text { Prone position supported with a thin pillow under the ankle and } \\
\text { abdomen } \\
\text { No popliteal fossa application }\end{array}$ \\
\hline $\begin{array}{l}\text { Hamstrings } \\
\text { spinae }\end{array}$ & Condyles of femur-lschial tuberosity & $\begin{array}{l}\text { Prone position supported with a thin pillow under the ankle and } \\
\text { abdomen }\end{array}$ \\
\hline
\end{tabular}




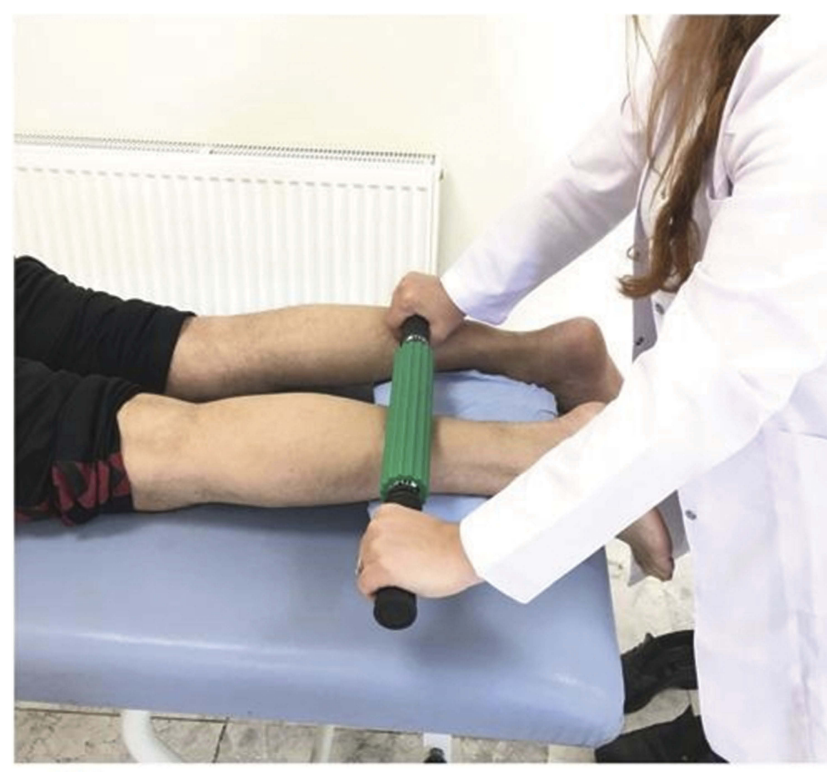

a

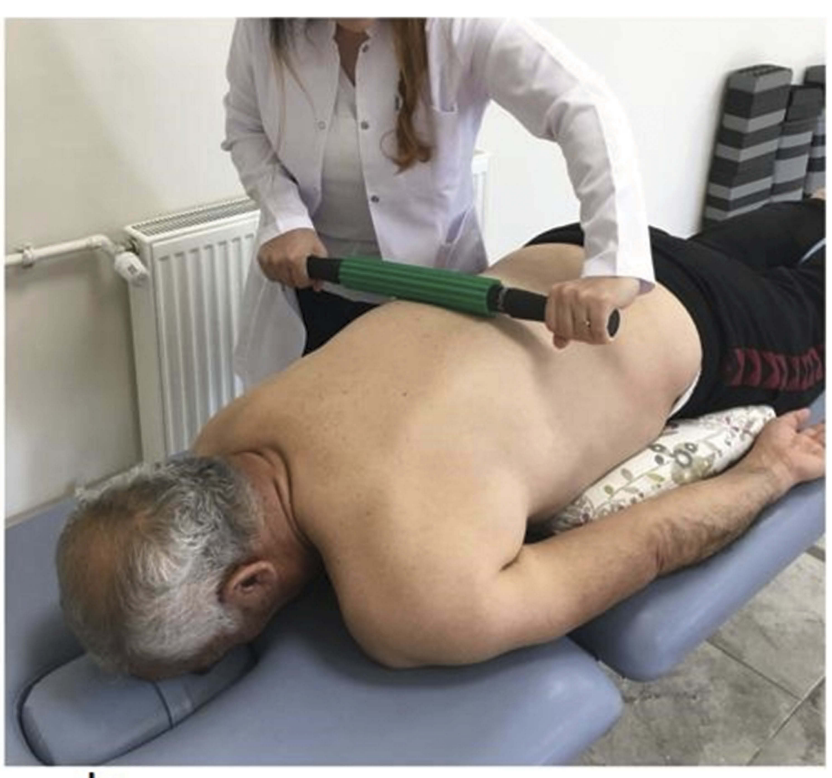

b

Figure 2 Examples of the roller massage application: gastrocnemius/achilles tendon (A), sacrolumbar fascia/erector spinae (B).

was used to determine the mean difference between before and after treatments. Changes over time within the groups and group-time interactions for continuous variables were assessed with mixed two-way repeated measures analysis of variance. The classification of effect sizes (f) was determined by calculating partial eta squared $(\mathrm{f}=0.10$ (small effects), $\mathrm{f}=0.25$ (medium effects) and $\mathrm{f}=0.40$ (large effects)). ${ }^{40}$

\section{Results}

Out of 47 patients assessed at baseline, two patients were excluded because they did not meet the inclusion criteria. Participants $(\mathrm{n}=45)$ were randomized into two groups (the CSE group, $n=23$; the CSE+MRT group, $n=22$ ). Two participants in the CSE group and one participant in the CSE+MRT group dropped out. Finally, the study was completed with 21 patients in the CSE group, and 21 patients in the CSE+MRT group (Figure 3).

Baseline characteristics of the participants in both groups were similar ( $\mathrm{p}>0.05$ ) (Table 3 ).

\section{Pain}

There was a statistically significant decrease in VAS at rest and VAS during activity values between pre- and postintervention in both groups $(p<0.001$, Table 4$)$. Moreover, there was a statistically significant increase in PPT values between pre- and post-intervention in both groups $(\mathrm{p}<0.001$, Table 4). There was no statistically significant between groups (group $\times$ time interactions) regarding VAS rest, VAS activity and PPT values ( $\mathrm{p}>0.05$, Table 4$)$.

\section{Low Back Disability}

There was a statistically significant decrease in ODI scores between pre- and post-intervention in both groups $(p<0.001$, Table 4). However, there was no statistically significant difference between the groups (group*time interactions) regarding ODI scores (p>0.05, Table 4).

\section{Lower Body Flexibility}

There was a statistically significant increase in CSRT values between pre- and post-intervention in the CSE + MRT group ( $p=0.016$, Table 4$)$ while the participants in the CSE group showed no significant changes ( $>0.05$, Table 4 ). There was no statistically significant difference between groups (group*time interactions) regarding CSRT values ( $>0.05$ Table 4$)$.

\section{Kinesiophobia}

There was no statistically significant difference in TSK scores between pre- and post-intervention in both groups ( $>0.05$ Table 4). Similarly, there was no statistically significant difference between groups (group $\times$ time interactions) regarding TSK scores ( $\mathrm{p}>0.05$ Table 4$)$. 


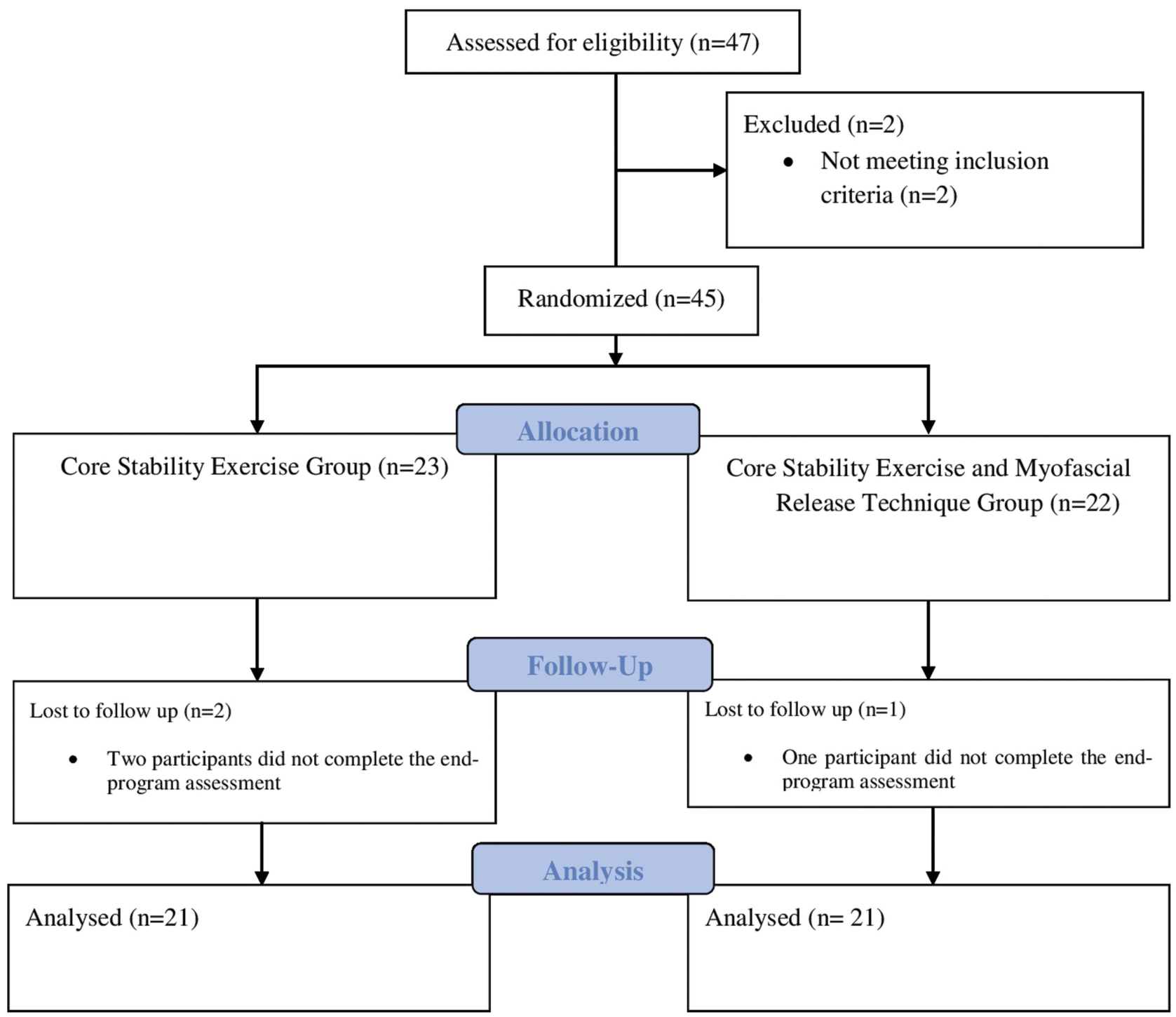

Figure 3 Study flow diagram.

\section{Core Stability Endurance}

According to our findings, the increase in SBT values was greater in the CSE+MRT group compared to the CSE group ( $\mathrm{p}=0.031$, Table 4$)$.

\section{Spinal Mobility}

According to our findings, the improvement in SAP values was greater in the CSE+MRT group compared to the CSE group ( $\mathrm{p}=0.022$, Table 4$)$.

Table 3 Baseline Characteristics Of Groups

\begin{tabular}{|l|l|l|l|}
\hline & CSE Group & CSE+MRT Group & p-Value \\
\hline Age (years) & $68.14 \pm 2.57$ & $68.04 \pm 2.97$ & $0.912^{\mathrm{a}}$ \\
Gender (male/female, \%) & $71.4 / 28.6$ & $69.0 / 31.0$ & $0.742^{\mathrm{b}}$ \\
Weigh (kg) & $79.66 \pm 11.84$ & $84.85 \pm 14.49$ & $0.211^{\mathrm{a}}$ \\
Height (cm) & $161.61 \pm 10.10$ & $164.00 \pm 7.48$ & $0.391^{\mathrm{a}}$ \\
Body mass index (kg/m $\left.{ }^{2}\right)$ & $30.70 \pm 5.47$ & $31.74 \pm 6.39$ & $0.577^{\mathrm{a}}$ \\
Pain duration (years) & $5.00(3.25-8.00)$ & $3.00(3.00-7.00)$ & $0.325^{\mathrm{c}}$ \\
MMSE score & $26.38 \pm 1.32$ & $26.33 \pm 1.77$ & $0.922^{\mathrm{a}}$ \\
\hline
\end{tabular}

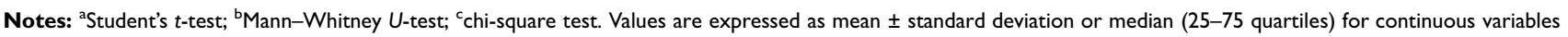
and frequencies were reported for categorical variables.

Abbreviation: MMSE: Mini-Mental State Examination. 
Table 4 Comparison Of Outcome Measures

\begin{tabular}{|c|c|c|c|c|c|c|c|c|}
\hline \multirow[t]{2}{*}{ Outcome Measures } & \multicolumn{2}{|l|}{ CSE Group } & \multirow[t]{2}{*}{$\mathbf{p}^{\prime}$-Value } & \multicolumn{2}{|c|}{ CSE+MRT Group } & \multirow[t]{2}{*}{$\mathbf{p}^{\prime}$-Value } & \multicolumn{2}{|l|}{$p^{2}$-Value } \\
\hline & Baseline & After & & Baseline & After & & Time & Group $\times$ Time \\
\hline \multicolumn{9}{|l|}{ Pain and disability } \\
\hline VAS rest $(\mathrm{cm})$ & $2.84 \pm 1.58$ & $1.30 \pm 1.13$ & $<0.001$ & $2.69 \pm 1.82$ & $1.50 \pm 1.30$ & $<0.001$ & $<0.001(0.690)$ & $0.222(0.037)$ \\
\hline VAS activity $(\mathrm{cm})$ & $5.68 \pm 1.26$ & $3.37 \pm 1.01$ & $<0.001$ & $6.19 \pm 1.79$ & $3.73 \pm 1.51$ & $<0.001$ & $<0.001(0.904)$ & $0.552(0.009)$ \\
\hline PPTs $\left(\mathrm{kg} / \mathrm{cm}^{2}\right)$ & $46.70 \pm 17.52$ & $62.64 \pm 16.91$ & $<0.001$ & $42.45 \pm 13.92$ & $56.00 \pm 13.48$ & $<0.001$ & $<0.001(0.687)$ & $0.452(0.014)$ \\
\hline ODI score & $56.47 \pm 11.22$ & $42.57 \pm 11.06$ & $<0.001$ & $61.52 \pm 16.16$ & $44.47 \pm 12.52$ & $<0.001$ & $<0.001(0.818)$ & $0.181(0.044)$ \\
\hline \multicolumn{9}{|l|}{ Lower body flexibility } \\
\hline CSRT $(\mathrm{cm})$ & $-3.80 \pm 10.12$ & $-3.09 \pm 9.54$ & 0.056 & $-6.19 \pm 10.98$ & $-5.19 \pm 9.90$ & 0.016 & $0.002(0.216)$ & $0.584(0.008)$ \\
\hline \multicolumn{9}{|l|}{ Kinesiophobia } \\
\hline TSK score & $43.57 \pm 5.93$ & $43.47 \pm 7.24$ & 0.893 & $46.76 \pm 7.21$ & $46.04 \pm 7.51$ & 0.096 & $0.324(0.024)$ & $0.450(0.014)$ \\
\hline \multicolumn{9}{|l|}{ Core stability endurance } \\
\hline SBT (s) & $104.95 \pm 70.85$ & $136.09 \pm 81.23$ & $<0.001$ & $96.09 \pm 58.33$ & $150.90 \pm 79.45$ & $<0.001$ & $<0.001(0.623)$ & $0.031(0.111)$ \\
\hline \multicolumn{9}{|l|}{ Spinal mobility } \\
\hline SAP spinal mobility, ${ }^{\circ}$ & $123.42 \pm 14.13$ & $126.04 \pm 14.55$ & 0.091 & $113.04 \pm 12.05$ & $122.42 \pm 15.33$ & 0.001 & $<0.001(0.307)$ & $0.022(0.123)$ \\
\hline CRP spinal mobility, ${ }^{\circ}$ & $45.61 \pm 8.82$ & $46.71 \pm 9.36$ & 0.581 & $43.09 \pm 9.73$ & $45.42 \pm 8.91$ & 0.214 & $0.206(0.040)$ & $0.645(0.005)$ \\
\hline \multicolumn{9}{|l|}{ Gait characteristics } \\
\hline WS $(\mathrm{m} / \mathrm{s})$ & $0.76 \pm 0.12$ & $0.77 \pm 0.17$ & 0.483 & $0.66 \pm 0.17$ & $0.68 \pm 0.13$ & 0.348 & $0.244(0.034)$ & $0.875(0.001)$ \\
\hline $\mathrm{SC}(\mathrm{m})$ & $0.78 \pm 0.08$ & $0.80 \pm 0.07$ & 0.136 & $0.70 \pm 0.15$ & $0.74 \pm 0.08$ & 0.210 & $0.094(0.068)$ & $0.458(0.014)$ \\
\hline$S L(m)(R)$ & $0.47 \pm 0.08$ & $0.47 \pm 0.10$ & 0.946 & $0.43 \pm 0.08$ & $0.45 \pm 0.08$ & 0.321 & $0.454(0.014)$ & $0.402(0.018)$ \\
\hline$S L(m)(L)$ & $0.48 \pm 0.08$ & $0.48 \pm 0.11$ & 0.787 & $0.45 \pm 0.07$ & $0.46 \pm 0.08$ & 0.719 & $0.651(0.005)$ & $0.928(<0.001)$ \\
\hline $\operatorname{CoV}(\mathrm{R})$ & $17.19 \pm 8.64$ & $|9.00 \pm| 2.5 \mid$ & 0.496 & $22.47 \pm 16.55$ & $19.00 \pm 14.19$ & 0.287 & $0.688(0.004)$ & $0.206(0.040)$ \\
\hline $\operatorname{CoV}(\mathrm{L})$ & $20.38 \pm 14.35$ & $22.28 \pm 14.52$ & 0.605 & $25.61 \pm 20.00$ & $20.33 \pm 18.45$ & 0.145 & $0.505(0.011)$ & $0.160(0.049)$ \\
\hline Time on foot (R) & $49.61 \pm 1.49$ & $49.90 \pm 1.13$ & 0.355 & $49.52 \pm 1.83$ & $49.85 \pm 1.55$ & 0.184 & $0.118(0.060)$ & $0.903(<0.001)$ \\
\hline Time on foot (L) & $50.14 \pm 1.38$ & $50.04 \pm 1.07$ & 0.748 & $50.47 \pm 1.83$ & $50.14 \pm 1.55$ & 0.184 & $0.265(0.031)$ & $0.534(0.010)$ \\
\hline Al & $87.76 \pm 4.67$ & $89.09 \pm 3.59$ & 0.100 & $83.61 \pm 6.67$ & $85.66 \pm 5.73$ & 0.047 & $0.009(0.157)$ & $0.567(0.008)$ \\
\hline \multicolumn{9}{|l|}{ Quality of life } \\
\hline WHOQOL-OLD score & $59.17 \pm 11.28$ & $64.38 \pm 11.30$ & $<0.001$ & $54.21 \pm 14.67$ & $60.86 \pm 13.29$ & $<0.001$ & $<0.001(0.767)$ & $0.171(0.046)$ \\
\hline
\end{tabular}

Notes: $p^{\prime}$, paired sample $t$-test; $p^{2}$, two-way repeated measures analysis of variance with a mixed model. Values are expressed as mean \pm standard deviation. Figures in parentheses are effect sizes.

Abbreviations: VAS, visual analog scale; PPTs, pressure pain thresholds; ODI, Oswestry Disability Index; CSRT, Chair Sit and Reach Test; TSK, Tampa Scale of Kinesiophobia; SBT, Supine Bridge Test; SAP, sagittal plane; CRP, coronal plane; WS, walking speed; SC, step cycle; SL, step length; CoV, coefficient of variation; Al, Ambulation Index; R, right; L, left.

There was no statistically significant difference in CRP values between pre- and post-intervention in both groups ( $>0.05$ Table 4). Similarly, there was no statistically significant difference between groups (group $\times$ time interactions) regarding CRP values ( $p>0.05$, Table 4$)$.

\section{Gait Characteristics}

There was no statistically significant difference between preand post-intervention in both groups regarding WS, SC, SL ( $\mathrm{R}$ and $\mathrm{L}$ ), $\mathrm{CoV}$ ( $\mathrm{R}$ and $\mathrm{L}$ ) and time on foot ( $\mathrm{R}$ and $\mathrm{L}$ ) values (p>0.05 Table 4). Likewise, there was no statistically significant difference between groups (group $\times$ time interactions) regarding the same values ( $>0.05$ Table 4 ).

There was a statistically significant increase in the AI value between pre- and post-intervention in the CSE+MRT group ( $p=0.047$, Table 4) while the participants in the CSE group showed no significant changes ( $>0.05$, Table 4 ). There was no statistically significant difference between groups (group $\times$ time interactions) regarding AI values ( $p>0.05$, Table 4 ).

\section{Quality Of Life}

There was a statistically significant increase in the WHOQOLOLD scores between pre- and post-intervention in both groups 
$(\mathrm{p}<0.001$, Table 4). However, there was no statistically significant difference between groups (group $\times$ time interactions) regarding WHOQOL-OLD scores ( $>0.05$, Table 4$)$.

\section{Discussion}

This is the first randomized controlled study investigating the effects of myofascial release technique combined with core stabilization exercises in elderly with NSLBP. In addition, the present study is the first study in which myofascial release technique is performed along SBL in LBP subjects. The findings of our study revealed that the improvement in core stability endurance and spinal mobility (in the sagittal plane) was greater in the CSE+MRT group compared to the CSE group.

A previous study found that core stabilization exercise program over the period of six weeksis more effective in terms of pain reduction, compared to routine physical therapy exercises for a similar duration in patients with NSLBP. ${ }^{41}$ In addition, a systematic review showed that a core stability exercise program is an effective method to alleviate chronic LBP. $^{42}$ Arguisuelas et al demonstrated that MRT displayed significant improvements in pain in patients with NSLBP. ${ }^{23}$ The findings of the present study are consistent with the results reported in the literature. Pain was found to decrease statistically in both groups. However, there was no statistically significant difference between the groups regarding pain. According to the literature as well as the present study, whether CSE and MRT are administered separately or together, both are effective in reducing pain in patients with NSLBP.

It is already reported in the literature that low PPTs in patients with chronic LBP are associated with the intensity of back pain and deterioration of physical functioning. ${ }^{43-45} \mathrm{In}$ addition, PPTs are lower in people with NSLBP compared to healthy subjects. ${ }^{44}$ Paungmali et al found that core stability exercises had a significant therapeutic effect as it increased the PPTs in patients with NSLBP. ${ }^{46}$ A study showed that MRT is an effective method to increase PPTs in patients with chronic pain. ${ }^{47}$ The results of our study were consistent with the literature. The present study found that PPTs increased in both groups. It is suggested that CSE+MRT is effective in increasing PPTs in patients with NSLBP.

The Oswestry Disability Index (ODI) is one of the most commonly used scales that assess the disability related to $\mathrm{LBP}^{26} \mathrm{~A}$ high pain level is associated with a high ODI score. ${ }^{48}$ A systematic review showed that a core stability exercise program is an effective method to improve ODI scores in patients with chronic LBP. ${ }^{42}$ It is found that MRT can reduce disability in patients with NSLBP. ${ }^{49}$ The findings of the present study are consistent with the results reported in the literature. A statistically significant decrease was reported in terms of disability in both groups. However, there was no statistically significant between the groups regarding ODI scores.

The CSRT is a safe and socially acceptable method to assess lower body flexibility especially hamstrings in older people. ${ }^{27}$ It is already reported that limited hamstring flexibility is associated with lower back pain. ${ }^{50}$ The literature suggests that a combination of core stability along with contract-relax exercises can increase hamstring flexibility. ${ }^{51}$ Our findings indicate that MRT of the superficial back line improves flexibility. ${ }^{52}$ The present study also showed a significant increase in lower body flexibility in the CSE+MRT group following the treatment. These results proved that MRT combined with CSE can improve lower extremity flexibility in elderly with NSLBP.

The TSK is usually used in clinical practice to quantify levels of pain-related fear of activity. ${ }^{28}$ Patients with LBP have a greater fear of movement. ${ }^{53,54}$ It is reported in the literature that back stability exercises can reduce TSK scores and fear of movement in patients with chronic LBP. $^{55}$ In addition, Arguisuelas et al found that MRT decreases fear-avoidance beliefs in patients with NSLBP. $^{23}$ Surprisingly and differently from the literature, in our study, there was no statistically significant difference between groups regarding TSK scores with no significant change in the TSK scores in both groups. This result can stem from the fact that the participants were elderly and had long durations of pain.

LBP causes motor control problems in core muscles that organize spinal movements and stability. ${ }^{56,57}$ SBT is used to assess core stability endurance. ${ }^{29}$ Our findings indicate that core stability exercises increase core stability endurance in patients with low back problem. ${ }^{58}$ Junker and Stöggl found that foam rolling as an MRT is an effective method to increase core stability endurance in healthy adults. ${ }^{59}$ Our findings are consistent with the results reported in the literature. However, the present study found that CSE+MRT is a more effective method to increase core stability endurance than CSE. We think that this is due to the increase in contractions on core muscles, especially transverse abdominis muscle after MRT. ${ }^{16}$

Spinal mobility is an important factor affecting daily activities especially in the elderly. ${ }^{60}$ Spinal mobility could also have an impact on postural control and performance during functional tasks. ${ }^{61}$ Our findings indicate that spinal 
mobility can be increased through core stability exercises in older people. ${ }^{61}$ In addition, Balasubramaniam et al found that MRT is an effective method to improve lumbar range of motion in mechanical back pain. ${ }^{62}$ The results of our study were consistent with the literature. The present study found that CSE+MRT is more effective than CSE in increasing core stability endurance.

Previous studies have shown that LBP is an independent factor affecting functional and walking performance. ${ }^{63,64} \mathrm{In}$ addition, older adults with LBP have slower gait speed than healthy old adults. ${ }^{65} \mathrm{Kim}$ et al reported that core stability exercises have a positive effect on gait function in elderly people. ${ }^{66}$ To the best of our knowledge, no study has investigated the effects of MRT on gait characteristics in patients with NSLBP. The present study showed that there was no statistically significant difference between groups regarding gait parameters except for ambulation index as well as no significant change in these values in both groups. Although ambulation index improved in CSE+MRT group, there was no statistically significant difference between the groups for the parameters of gait. The effects of CSE+MRT on gait parameters should be investigated in future studies.

LBP often affects a variety of physical and psychosocial health domains. ${ }^{67,68}$ Patients with LBP have a poorer quality of life. ${ }^{53,69}$ Our findings show that core stability exercise program is a helpful treatment option for improving quality of life in patients with LBP. ${ }^{70}$ Although the evidence is insufficient, MRT is shown to be an effective method in improving quality of life in patients with chronic pain. ${ }^{22}$ The findings of the present study are consistent with the results reported in the literature. Quality of life was found to improve in both groups. However, there was no statistically significant difference between the groups. The literature and our study showed that whether CSE and MRT are administered separately or together, both are effective in improving the quality of life in patients with NSLBP.

\section{Limitations Of The Study}

This study has several limitations that should be considered. First, although the patients were divided into two groups as the CSE group and CSE+MRT group, an additional MRT group could also be formed as a third group. The presence of an MRT group as a third group could have demonstrated separately the effectiveness of each treatment.

Second, myofascial relaxation technique was performed with a roller massager in this study. Although roller massage application is considered as one of the myofascial release techniques, many other methods also exist (for example, osteopathic soft tissue techniques, strain counter strain, myofascial trigger point therapy, muscle energy technique). The effects of each of these methods may be different. In further studies, the effects of these different methods should also be investigated. Additionally, although roller massage application was performed in accordance with the current literature, there is a lack of knowledge in the literature regarding the intensity and time of application, rest periods and number of sets. This may affect the results. Further studies are needed.

\section{Conclusions}

This is the first randomized controlled study investigating the impact of myofascial release technique with a roller massager combined with core stabilization in elderly with NSLBP. CSE+MRT is more effective than CSE in terms of a greater increase in core stability endurance and spinal mobility in patients with NSLBP. These results suggest that myofascial release technique with a roller massager combined with core stabilization can be a choice for treating NSLBP in elderly.

\section{Data Sharing}

Deidentified data are accessible on request via e-mail to the corresponding author. Including, demographic characteristics, pain, lower back disability, lower body flexibility, kinesiophobia, core stability endurance, spinal mobility, gait characteristics and quality of life. The study protocol, statistical analysis plan and informed consent are also available.

\section{Disclosure}

The authors report no conflicts of interest in this work.

\section{References}

1. Golob AL, Wipf JE. Low back pain. Med Clin North Am. 2014;98 (3):405-428. doi:10.1016/j.mcna.2014.01.003

2. Beyera GK, O’Brien J, Campbell S. Health-care utilisation for low back pain: a systematic review and meta-analysis of population-based observational studies. Rheumatol Int. 2019. doi:10.1007/s00296-019-04430-5

3. Maher C, Underwood M, Buchbinder R. Non-specific low back pain. Lancet (London, England). 2017;389(10070):736-747. doi:10.1016/ S0140-6736(16)30970-9

4. El-Sayed AM, Hadley C, Tessema F, Tegegn A, Cowan JA Jr., Galea S. Back and neck pain and psychopathology in rural sub-Saharan Africa: evidence from the Gilgel Gibe Growth and Development Study, Ethiopia. Spine. 2010;35(6):684-689. doi:10.1097/BRS.0b013e3181b4926e

5. Hoy D, March L, Brooks P, et al. The global burden of low back pain: estimates from the global burden of disease 2010 study. Ann Rheum Dis. 2014;73(6):968-974. doi:10.1136/annrheumdis-2013-204428

6. Jones LD, Pandit H, Lavy C. Back pain in the elderly: a review. Maturitas. 2014;78(4):258-262. doi:10.1016/j.maturitas.2014.05.004

7. Nascimento P, Costa LOP, Araujo AC, Poitras S, Bilodeau M. Effectiveness of interventions for non-specific low back pain in older adults. A systematic review and meta-analysis. Physiotherapy. 2019;105(2):147-162. doi:10.1016/j.physio.2018.11.004 
8. Gatton ML, Pearcy MJ, Pettet GJ, Evans JH. A three-dimensional mathematical model of the thoracolumbar fascia and an estimate of its biomechanical effect. J Biomech. 2010;43(14):2792-2797.

9. Wilke J, Schleip R, Klingler W, Stecco C. The lumbodorsal fascia as a potential source of low back pain: a narrative review. Biomed Res Int. 2017;2017:5349620.

10. Myers TW. Anatomy Trains E-Book: Myofascial Meridians for Manual and Movement Therapists. Elsevier Health Sciences; 2013.

11. Barker PJ, Urquhart DM, Story IH, Fahrer M, Briggs CA. The middle layer of lumbar fascia and attachments to lumbar transverse processes: implications for segmental control and fracture. Eur Spine J. 2007;16(12):2232-2237. doi:10.1007/s00586-007-0502-Z

12. Barker PJ, Briggs CA. Attachments of the posterior layer of lumbar fascia. Spine. 1999;24(17):1757-1764. doi:10.1097/00007632-19990 9010-00002

13. Wilke J, Macchi V, De Caro R, Stecco C. Fascia thickness, aging and flexibility: is there an association? J Anat. 2019;234(1):43-49. doi:10.1111/joa.12902

14. Hides JA, Belavy DL, Cassar L, Williams M, Wilson SJ, Richardson CA. Altered response of the anterolateral abdominal muscles to simulated weight-bearing in subjects with low back pain. Eur Spine J. 2009;18(3):410-418. doi:10.1007/s00586-008-0827-2

15. Hodges PW, Richardson CA. Inefficient muscular stabilization of the lumbar spine associated with low back pain. A motor control evaluation of transversus abdominis. Spine. 1996;21(22):2640-2650. doi:10.1097/00007632-199611150-00014

16. Chen YH, Chai HM, Shau YW, Wang CL, Wang SF. Increased sliding of transverse abdominis during contraction after myofascial release in patients with chronic low back pain. Man Ther 2016;23:69-75. doi:10.1016/j.math.2015.10.004

17. Jorgensen JE, Afzali T, Riis A. Effect of differentiating exercise guidance based on a patient's level of low back pain in primary care: a mixed-methods systematic review protocol. BMJ Open 2018;8(1):e019742. doi:10.1136/bmjopen-2017-019742

18. O'Connell NE, Cook CE, Wand BM, Ward SP. Clinical guidelines for low back pain: A critical review of consensus and inconsistencies across three major guidelines. Best Pract Res Clin Rheumatol. 2016;30(6):968-980. doi:10.1016/j.berh.2017.05.001

19. Hodges PW. Core stability exercise in chronic low back pain. Orthop Clin North Am. 2003;34(2):245-254.

20. Wang XQ, Zheng JJ, Yu ZW, et al. A meta-analysis of core stability exercise versus general exercise for chronic low back pain. PLoS One. 2012;7(12):e52082. doi:10.1371/journal.pone.0052082

21. Kim M, Kim M, Oh S, Yoon B. The effectiveness of hollowing and bracing strategies with lumbar stabilization exercise in older adult women with nonspecific low back pain: a quasi-experimental study on a community-based rehabilitation. J Manipulative Physiol Ther. 2018;41(1):1-9. doi:10.1016/j.jmpt.2017.06.012

22. Laimi K, Makila A, Barlund E, et al. Effectiveness of myofascial release in treatment of chronic musculoskeletal pain: a systematic review. Clin Rehabil. 2018;32(4):440-450. doi:10.1177/0269215517732820

23. Arguisuelas MD, Lison JF, Sanchez-Zuriaga D, Martinez-Hurtado I, Domenech-Fernandez J. Effects of myofascial release in nonspecific chronic low back pain: a randomized clinical trial. Spine. 2017;42 (9):627-634. doi:10.1097/BRS.0000000000001897

24. Hawker GA, Mian S, Kendzerska T, French M. Measures of adult pain: Visual Analog Scale for Pain (VAS Pain), Numeric Rating Scale for Pain (NRS Pain), McGill Pain Questionnaire (MPQ), Short-Form McGill Pain Questionnaire (SF-MPQ), Chronic Pain Grade Scale (CPGS), Short Form-36 Bodily Pain Scale (SF-36 BPS), and Measure of Intermittent and Constant Osteoarthritis Pain (ICOAP). Arthritis Care Res (Hoboken). 2011;63(Suppl 11):S240-S252.

25. Farasyn A, Lassat B. Cross friction algometry (CFA): comparison of pressure pain thresholds between patients with chronic non-specific low back pain and healthy subjects. J Bodyw Mov Ther. 2016;20 (2):224-234. doi:10.1016/j.jbmt.2015.09.005
26. Fairbank JC, Pynsent PB. The oswestry disability index. Spine. 2000;25(22):2940-2952; discussion 2952. doi:10.1097/00007632200011150-00017

27. Jones CJ, Rikli RE, Max J, Noffal G. The reliability and validity of a chair sit-and-reach test as a measure of hamstring flexibility in older adults. Res $Q$ Exerc Sport. 1998;69(4):338-343. doi:10.1080/ 02701367.1998 .10607708

28. Vlaeyen JW, Kole-Snijders AM, Boeren RG, van Eek H. Fear of movement/(re)injury in chronic low back pain and its relation to behavioral performance. Pain. 1995;62(3):363-372. doi:10.1016/ 0304-3959(94)00279-n

29. Schellenberg KL, Lang JM, Chan KM, Burnham RS. A clinical tool for office assessment of lumbar spine stabilization endurance: prone and supine bridge maneuvers. Am J Phys Med Rehabil. 2007;86 (5):380-386. doi:10.1097/PHM.0b013e318032156a

30. Seichert N, Baumann M, Senn E, Zuckriegl HJPRKM. The "back mouse"-an analog-digital measuring device to record the sagittal outline of the back. Phys Rehab Kur Med. 1994;4(35-43):35-43.

31. Newell D, Shead V, Sloane L. Changes in gait and balance parameters in elderly subjects attending an 8-week supervised Pilates programme. J Bodyw Mov Ther. 2012;16(4):549-554. doi:10.1016/j. jbmt.2012.02.002

32. Gobbens RJ, Remmen R. The effects of sociodemographic factors on quality of life among people aged 50 years or older are not unequivocal: comparing SF-12, WHOQOL-BREF, and WHOQOL-OLD. Clin Interv Aging. 2019;14:231-239. doi:10.2147/CIA.S189560

33. Akuthota V, Ferreiro A, Moore T, Fredericson M. Core stability exercise principles. Curr Sports Med Rep. 2008;7(1):39-44. doi:10.1097/01.CSMR.0000308663.13278.69

34. Baerga-Varela L, Abreu Ramos AM. Core strengthening exercises for low back pain. Bol Asoc Med P R. 2006;98(1):56-61.

35. Cheatham SW, Stull KR. Roller massage: A commentary on clinical standards and survey of physical therapy professionals - Part 1. Int J Sports Phys Ther. 2018;13(4):763-772.

36. Cavanaugh MT, Doweling A, Young JD, et al. An acute session of roller massage prolongs voluntary torque development and diminishes evoked pain. Eur J Appl Physiol. 2017;117(1):109-117. doi:10.1007/s00421-016-3503-y

37. Halperin I, Aboodarda SJ, Button DC, Andersen LL, Behm DG. Roller massager improves range of motion of plantar flexor muscles without subsequent decreases in force parameters. Int J Sports Phys Ther. 2014;9(1):92-102.

38. Aboodarda SJ, Spence AJ, Button DC. Pain pressure threshold of a muscle tender spot increases following local and non-local rolling massage. BMC Musculoskelet Disord. 2015;16:265.

39. Henry Joseph L, Hancharoenkul B, Sitilertpisan P, Pirunsan U, Paungmalia A. Comparison of effects between core stability training and sports massage therapy among elite weightlifters with chronic non-specific low back pain: A randomized cross-over study. Asian J Sports Med. 2018;9:1. doi:10.5812/asjsm

40. Maher JM, Markey JC, Ebert-May D. The other half of the story: effect size analysis in quantitative research. CBE Life Sci Educ. 2013;12(3):345-351. doi:10.1187/cbe.13-04-0082

41. Akhtar MW, Karimi H, Gilani SA. Effectiveness of core stabilization exercises and routine exercise therapy in management of pain in chronic non-specific low back pain: A randomized controlled clinical trial. PakJ Med Sci. 2017;33(4):1002-1006. doi:10.12669/pjms.334.12664

42. Chang WD, Lin HY, Lai PT. Core strength training for patients with chronic low back pain. J Phys Ther Sci. 2015;27(3):619-622. doi:10.1589/jpts.27.619

43. Clauw DJ, Williams D, Lauerman W, et al. Pain sensitivity as a correlate of clinical status in individuals with chronic low back pain. Spine. 1999;24(19):2035-2041. doi:10.1097/00007632-199910010-00013

44. Farasyn A, Meeusen R. The influence of non-specific low back pain on pressure pain thresholds and disability. Eur J Pain. 2005;9 (4):375-381. doi:10.1016/j.ejpain.2004.09.005 
45. Goubert D, Meeus M, Willems T, et al. The association between back muscle characteristics and pressure pain sensitivity in low back pain patients. Scand J Pain. 2018;18(2):281-293. doi:10.1515/sjpain-20170142

46. Paungmali A, Joseph LH, Sitilertpisan P, Pirunsan U, Uthaikhup S. Lumbopelvic core stabilization exercise and pain modulation among individuals with chronic nonspecific low back pain. Pain Pract. 2017;17(8):1008-1014. doi:10.1111/papr.12552

47. Rodriguez-Huguet M, Gil-Salu JL, Rodriguez-Huguet P, CabreraAfonso JR, Lomas-Vega R. Effects of myofascial release on pressure pain thresholds in patients with neck pain: a single-blind randomized controlled trial. Am J Phys Med Rehabil. 2018;97(1):16-22. doi:10.1097/PHM.0000000000000790

48. Andrusaitis SF, Brech GC, Vitale GF, Greve JM. Trunk stabilization among women with chronic lower back pain: a randomized, controlled, and blinded pilot study. Clinics (Sao Paulo). 2011;66 (9):1645-1650. doi:10.1590/s1807-59322011000900024

49. Arguisuelas MD, Lison JF, Domenech-Fernandez J, MartinezHurtado I, Salvador Coloma P, Sanchez-Zuriaga D. Effects of myofascial release in erector spinae myoelectric activity and lumbar spine kinematics in non-specific chronic low back pain: randomized controlled trial. Clin Biomech (Bristol, Avon). 2019;63:27-33. doi:10.1016/j.clinbiomech.2019.02.009

50. Frey M, Poynter A, Younge K, De Carvalho D. The relationship between lumbopelvic flexibility and sitting posture in adult women. J Biomech. 2019;84:204-210. doi:10.1016/j.jbiomech.2018.12.048

51. Na'ima A, Sari G, Utomo D. Combination effect of core stability exercise and contract relax exercise on hamstring flexibility. Paper presented at:

52. Williams W, Selkow NM. Self-myofascial release of the superficial back line improves sit-and-reach distance. J Sport Rehabil. Epub 2019, Mar 12.

53. Antunes RS, de Macedo BG, Amaral Tda S, Gomes Hde A, Pereira LS, Rocha FL. Pain, kinesiophobia and quality of life in chronic low back pain and depression. Acta Ortop Bras. 2013;21(1):27-29. doi:10.1590/S1413-78522013000100005

54. Bunzli S, Smith A, Watkins R, Schutze R, O'Sullivan P. What do people who score highly on the tampa scale of kinesiophobia really believe? A mixed methods investigation in people with chronic nonspecific low back pain. Clin J Pain. 2015;31(7):621-632. doi:10.1097/AJP.0000000000000143

55. Norris C, Matthews M. The role of an integrated back stability program in patients with chronic low back pain. Complement Ther Clin Pract. 2008;14(4):255-263. doi:10.1016/j.ctcp.2008.06.001

56. Hodges PW, Moseley GL. Pain and motor control of the lumbopelvic region: effect and possible mechanisms. J Electromyogr Kinesiol. 2003;13(4):361-370.

57. Russo M, Deckers K, Eldabe S, et al. Muscle control and non-specific chronic low back pain. Neuromodulation. 2018;21(1):1-9. doi:10. $1111 /$ ner. 12738
58. Bayraktar D, Guclu-Gunduz A, Lambeck J, Yazici G, Aykol S, Demirci H. A comparison of water-based and land-based core stability exercises in patients with lumbar disc herniation: a pilot study. Disabil Rehabil. 2016;38(12):1163-1171. doi:10.3109/09638288.2015.1075608

59. Junker D, Stoggl T. The training effects of foam rolling on core strength endurance, balance, muscle performance and range of motion: a randomized controlled trial. J Sports Sci Med. 2019;18 (2):229-238.

60. Bergstrom G, Aniansson A, Bjelle A, Grimby G, Lundgren-Lindquist B, Svanborg A. Functional consequences of joint impairment at age 79. Scand J Rehabil Med. 1985;17(4):183-190.

61. Granacher U, Lacroix A, Muehlbauer T, Roettger K, Gollhofer A. Effects of core instability strength training on trunk muscle strength, spinal mobility, dynamic balance and functional mobility in older adults. Gerontology. 2013;59(2):105-113. doi:10.1159/ 000343152

62. Balasubramaniam A, Ghandi VM, Sambandamoorthy A, Sciences B. Role of myofascial release therapy on pain and lumbar range of motion in mechanical back pain: an exploratory investigation of desk job workers. Ibnosina J Med Biomed Sci. 2014;6(2):75-80.

63. Reid MC, Williams CS, Gill TM. Back pain and decline in lower extremity physical function among community-dwelling older persons. J Gerontol A Biol Sci Med Sci. 2005;60(6):793-797. doi:10.1093/gerona/60.6.793

64. Rudy TE, Weiner DK, Lieber SJ, Slaboda J, Boston JR. The impact of chronic low back pain on older adults: a comparative study of patients and controls. Pain. 2007;131(3):293-301. doi:10.1016/j. pain.2007.01.012

65. Hicks GE, Sions JM, Coyle PC, Pohlig RT. Altered spatiotemporal characteristics of gait in older adults with chronic low back pain. Gait Posture. 2017;55:172-176. doi:10.1016/j.gaitpost.2017.04.027

66. Kim NJ, Kim JS, Wang JS, Park JH, Choi JH. The effects of isometric trunk exercises and dynamic trunk exercises on gait in elderly people. $J$ Phys Ther Sci. 2015;27(6):1685-1689. doi:10.1589/jpts.27.1685

67. Husky MM, Ferdous Farin F, Compagnone P, Fermanian C, KovessMasfety V. Chronic back pain and its association with quality of life in a large French population survey. Health Qual Life Outcomes. 2018;16(1):195. doi:10.1186/s12955-018-1018-4

68. Deyo RA, Andersson G, Bombardier C, et al. Outcome measures for studying patients with low back pain. Spine. 1994;19(18 Suppl):2032s-2036s. doi:10.1097/00007632-199409151-00003

69. Kovacs FM, Abraira V, Zamora J, et al. Correlation between pain, disability, and quality of life in patients with common low back pain. Spine. 2004;29(2):206-210. doi:10.1097/01.BRS.0000107235.47465.08

70. Noormohammadpour P, Kordi M, Mansournia MA, AkbariFakhrabadi M, Kordi R. The role of a multi-step core stability exercise program in the treatment of nurses with chronic low back pain: a single-blinded randomized controlled trial. Asian Spine J. 2018;12(3):490-502. doi:10.4184/asj.2018.12.3.490
Clinical Interventions in Aging

\section{Publish your work in this journal}

Clinical Interventions in Aging is an international, peer-reviewed journal focusing on evidence-based reports on the value or lack thereof of treatments intended to prevent or delay the onset of maladaptive correlates of aging in human beings. This journal is indexed on PubMed Central, MedLine, CAS, Scopus and the Elsevier
Bibliographic databases. The manuscript management system is completely online and includes a very quick and fair peer-review system, which is all easy to use. Visit http://www.dovepress.com/ testimonials.php to read real quotes from published authors. 